\title{
Internet marketing in the field of higher education
}

\author{
Angelina Beuzova ${ }^{1}$, Natalya Tovma ${ }^{1,}{ }^{*}$, Irina Maslova $^{2}$, Marina Vasileva $^{2}$, Inna \\ Mishchenko $^{3}$, and Nazym Tulebayeva ${ }^{1}$ \\ ${ }^{1}$ Al-Farabi Kazakh National University, 71/24 Al-Farabi, 50040, Almaty, Kazakhstan \\ ${ }^{2}$ Orel State University named after I.S. Turgenev, 302020 Orel, Russia \\ ${ }^{3}$ Altai State University, 656049 Barnaul, Russia
}

\begin{abstract}
Competition in the education sector is growing every year. Students have the opportunity to embark in both domestic and foreign universities. In prior years, universities did not put a large budget in the promotion, as the demand exceeded the supply. Kazakhstan's accession to the international market of educational services has increased the need to use effective promotion tools. Marketing is an important element in attracting students. With the development of technology, the role of the Internet increases, which becomes an integral part of marketing. Internet marketing in the field of higher education has great prospects. The key features of this direction are low cost and high efficiency. At the same time, the promotion takes place not only on the regional but also on the global market. Today, promotion and advertising using the Internet is replacing traditional marketing. The article analyzes various Internet marketing tools that apply to the field of higher education. The creation and development of corporate websites of the university is an important stage of promotion. The corporate site must have certain characteristics to attract a potential student. A person spends most of the day on social networks, which are also an Internet marketing tool. Maintaining the image of the university requires the creation of official pages in social networks. These platforms create conditions for cooperation with students, applicants and graduates. Competent use of internet marketing will allow developing the sphere of higher education.
\end{abstract}

\section{Introduction}

At the present stage, the development of Kazakhstan's higher education takes place in market conditions. The number of non-profit universities is growing, and government funding is declining every year. At the same time, almost all universities have similar educational programs, which reduces the level of memorization of the educational institution by a potential student. In such conditions, there is a "struggle" to attract the attention of each applicant. The effectiveness of university promotion depends on the marketing tools used. The most simple, convenient and modern tool is the Internet.

\footnotetext{
*Corresponding author: nataliya-tovma@mail.ru
} 
Today, the Internet plays an important role in marketing. According to the group of communication agencies Dentsu Aegis Network Kazakhstan, about 9.3 million people in Kazakhstan are Internet users. Of these, more than $90 \%$ are registered in at least one Social Network, and these indicators are constantly growing. [1]

The development of Internet marketing took place with the development of Internet technologies. Today it is one of the cheapest and most successful promotion tools. Internet marketing is the activity of attracting and retaining consumers through the organization of marketing on the Internet.

Internet marketing of the university can be defined as follows: This is a consistent process aimed at solving marketing tasks, in particular, attracting and meeting the needs of applicants in educational services using Internet tools. With their help, universities prove their competitive advantages to consumers. The Internet allows you to reach not only regional but also international markets of consumers of educational services.

\section{Materials and methods}

The authors conducted a study to determine the role of Internet marketing in the promotion of the university.

- a search and analysis of information on the dynamics of the number of higher educational institutions in Kazakhstan we conducted;

- the data of Internet Usage Statistics on the use of the Internet in the world are analyzed;

- the indicators of The number of users of social networks around the world from 2017 to 2025 were studied and a chart of popular Social networks in the world was compiled;

- the most important indicators of evaluating the effectiveness of the university's website are analyzed;

- conclusions are drawn on the influence of Internet marketing on the promotion of the university among applicants and students.

\section{Results}

Along with this, there is high competition with foreign educational institutions. Every year, out of 100 thousand Kazakhstani graduates, about $20 \%$ choose to study abroad. Such countries divide into four groups. (Figure 1)

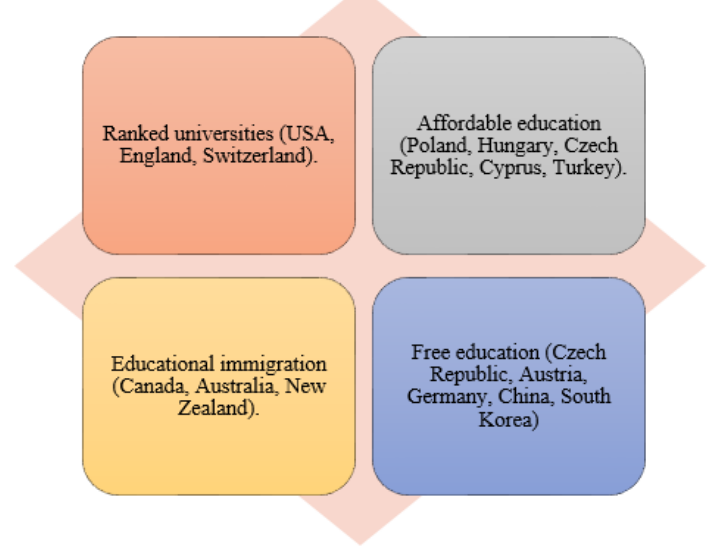

Fig. 1. Groups of countries preferred by Kazakhstani applicants (compiled by the authors). 
According to Figure 1, the first group is the countries where the ranked universities are located. The cost of training there is quite high, as well as the cost of living and food. The second group is countries with more affordable prices for education and accommodation. The third group includes paid educational programs with the possibility of immigration abroad. The last group is the countries where Kazakhstan students can study for free, but at the same time in their native language of this country. The most popular areas of study are Business and Technology [2].

The development of organizations in the field of higher education is connected with the ways of their positioning in the market. Using marketing to promote universities is becoming one of the most important elements of further development in Kazakhstan. Each university uses its own marketing strategies, and the history of its creation and development become elements of PR. I. V. Zinovieva defines three stages of the development of marketing of educational services in Russia, which apply to the Kazakh market:

- development of marketing focused on the production of educational products and services (internal monitoring);

- development of sales-oriented marketing (monitoring of the educational services market);

- development of demand-driven marketing. [3]

The first stage refers to the "Soviet" period of development of higher education. A distinctive feature is a planned economy and a focus on improving the quality of educational services.

The second stage begins with the advent of independence in 1991. Universities adapt to market realities and focus on the "earning process". This stage is characterized by the commercialization of higher education. At the same time, the majority of applicants entered the economic specialties, while the number of graduates working in the specialty was low. At this stage, the main means of attracting future students was career guidance work - trips to schools, in order to inform about the conditions of admission, the advantages of the university and invitation to an "open day", etc. These tools are still used today, although their effectiveness is gradually decreasing.

The demand for education services exceeded the supply, which led to an increase in the number of private universities in the country (table 1).

Table 1. Number of higher educational institutions in Kazakhstan, units [4]

\begin{tabular}{|c|c|c|c|c|c|}
\hline & 2000 & 2005 & 2010 & 2015 & 2019 \\
\hline Republic of Kazakhstan & 170 & 181 & 149 & 127 & 125 \\
\hline Akmola region & 7 & 8 & 6 & 6 & 4 \\
\hline Aktobe region & 5 & 7 & 8 & 6 & 6 \\
\hline Almaty region & 3 & 4 & 2 & 3 & 3 \\
\hline Atyrau region & 3 & 3 & 3 & 3 & 3 \\
\hline West-Kazakhstan region & 5 & 7 & 4 & 3 & 4 \\
\hline Zhambyl region & 4 & 5 & 5 & 4 & 3 \\
\hline Karagandy region & 17 & 15 & 13 & 9 & 9 \\
\hline Kostanay region & 8 & 9 & 7 & 7 & 7 \\
\hline Kyzylorda region & 7 & 6 & 5 & 4 & 3 \\
\hline Mangystau region & 4 & 3 & 3 & 2 & 2 \\
\hline Pavlodar region & 4 & 4 & 4 & 4 & 4 \\
\hline North-Kazakhstan region & 2 & 4 & 2 & 2 & 2 \\
\hline Turkestan region & 5 & 2 & 2 & 2 & 2 \\
\hline East-Kazakhstan region & 11 & 10 & 10 & 7 & 7 \\
\hline Nur-Sultan & 6 & 11 & 13 & 14 & 15 \\
\hline Almaty & 68 & 66 & 52 & 42 & 41 \\
\hline Shymkent & 11 & 17 & 10 & 9 & 10 \\
\hline
\end{tabular}


According to table 1, the growth in the number of higher education institutions in Kazakhstan continued until 2010. The largest number of universities is concentrated in Almaty. The number of universities is gradually decreasing. This is due to a decrease in state funding, increased requirements for the quality of education and teaching staff. The increase in requirements is the result of Kazakhstan's accession to the Bologna Process, and this is the beginning of the third stage. Higher educational institutions are actively working to attract students, and specialized exhibitions have been created. Universities have websites and pages in social networks where they tell about the social life of students.

Kazakhstan's education entered the international market with the transition to a threelevel model of training specialists, as well as the development of academic mobility. (Table 2).

Table 2. Share of foreign students of higher educational institutions in Kazakhstan, \% [4]

\begin{tabular}{|c|c|c|c|c|c|}
\hline & 2000 & 2005 & 2010 & 2015 & 2019 \\
\hline Republic of Kazakhstan & 1,4 & 1,4 & 1,7 & 2,4 & 6,5 \\
\hline Akmola region & 0,1 & 0,4 & 0,3 & 0,6 & 1,2 \\
\hline Aktobe region & 0,3 & 0,5 & 0,5 & 0,7 & 5,1 \\
\hline Almaty region & 1,4 & 0,5 & 0,1 & 1,3 & 2,0 \\
\hline Atyrau region & 0,2 & 0,2 & 0,1 & 1,9 & 3,1 \\
\hline West-Kazakhstan region & 1,6 & 0,7 & 0,8 & 0,5 & 0,8 \\
\hline Zhambyl region & 0,7 & 1,4 & 0,5 & 2,7 & 8,2 \\
\hline Karagandy region & 0,7 & 1,0 & 1,1 & 3,5 & 4,5 \\
\hline Kostanay region & 0,3 & 0,8 & 1,2 & 1,4 & 1,5 \\
\hline Kyzylorda region & 0,8 & 0,4 & 3,9 & 0,0 & 0,4 \\
\hline Mangystau region & 3,2 & 3,4 & 2,1 & 5,5 & 13,1 \\
\hline Pavlodar region & 0,4 & 0,5 & 0,5 & 1,0 & 1,9 \\
\hline North-Kazakhstan region & 1,5 & 1,8 & 1,3 & 2,2 & 3,8 \\
\hline Turkestan region & 7,7 & 4,6 & 6,7 & 10,0 & 15,2 \\
\hline East-Kazakhstan region & 0,8 & 1,3 & 1,2 & 2,4 & 3,3 \\
\hline Nur-Sultan city & 0,5 & 0,7 & 1,0 & 1,6 & 2,4 \\
\hline Almaty city & 1,6 & 2,3 & 2,3 & 2,9 & 4,4 \\
\hline Shymkent city & 3,3 & 1,2 & 2,5 & 2,7 & 18,0 \\
\hline
\end{tabular}

As can be seen from Table 2, Kazakhstan's accession to the Bologna Process has influenced the increase in the share of foreign students in domestic universities. If in 2010 their number was $1.7 \%$ of the total number of students, by now this figure has grown to $6.5 \%$. The largest percentage of foreign students falls in the city of Shymkent, as well as on the Mangystau and Turkestan regions. This owes to most international students come from Uzbekistan, Turkmenistan, Kyrgyzstan, India and China. If for the latter, the highest priority is the universities of the city of Almaty, then the rest come to study in the regions closest to the borders.

At the present stage of development, the marketing of educational services is moving away from traditional methods of career guidance and is more personalized. The most successful marketing tools in the field of education are advertising, PR and promotion on the Internet.

Advertising is a well-known marketing tool for the university. This is not traditional marketing, but new types of promotion - digital, contextual, banner advertising on the Internet. The most popular platforms used by digital advertising are Google, Facebook, and Twitter. [5] Contextual advertising adapts to the page content and user preferences. That is, when searching keywords in the search engine (university, higher education), a specially configured ad will be displayed. Alternatively, if the user viewed sites with similar content 
some time ago, they will see ads in the search engine. Banner ads have similar properties. When viewing similar pages or after entering keywords, the potential consumer will meet the corresponding banner, has a hyperlink to the official website of the university. It may contain information about the areas of training, entrance exams, threshold score, competitive advantages of the university and other information that may attract the attention and interest of the future applicant.

One of the tools of Internet marketing is Email marketing, which involves promotion using email newsletters. It will be effective if the applicant is interested in receiving mailings and if there are, e-mail addresses of potential students. They get into the university's database through educational exhibitions, were not only domestic but also foreign universities participate, and anyone can leave their data for various mailings.

Currently, the popularity of SEO promotion is increasing. This is search engine optimization, which consists of two tasks: the first is to set up a website so that a search engine such as Google can index it correctly. The second is to make the site appear in the top search results for a product or service [6]. However, it is possible to use this Internet marketing tool if there is a university website.

The corporate site is the "face" of the university, but many educational institutions have the problem of creating effective websites. [7] D. A. Shevchenko highlighted the following important indicators for evaluating the effectiveness of the university's website:

- Design;

- Navigation;

- Content;

- Interactivity;

- Site visibility on the Internet. [8]

A good website is designed in the same style as easy-to-read fonts and is conveniently designed. Besides, the design should be cross-browser and cross-platform, that is, adapted to different platforms and browser versions.

The information that is broadcast on the site is also called content. This includes information about the curriculum, the educational process, the structure of the university, the admission committee, student life, accreditation, cooperation, as well as contacts. All the information provided should be structured and divided into sections.

Interactivity means the presence of feedback, links to the university's social networks, constant updating of information, and the possibility of registration.

Internet marketing includes posting information about the university on industry portals, maintaining a university blog, and SMM.

Industry portals are intermediaries between applicants and universities; they provide interested users with information and links to the official website. For example, there are websites in Russia www.postupi.online and others, where all the existing universities of the country are located. The applicant gets to the main page, where he can choose the subjects of the Unified State Exam that he planned or already passed. After that, a list of all the universities that you can enter in these areas, as well as the available specialties, opens.

Using the promotion of educational services through social networks and the Internet has great potential. Every year, the number of Internet users is growing, on average, by $8.2 \%$. In 2020, it was about $59 \%$ of the total population of the Earth (4.8 B). (Fig. 2) [9] 


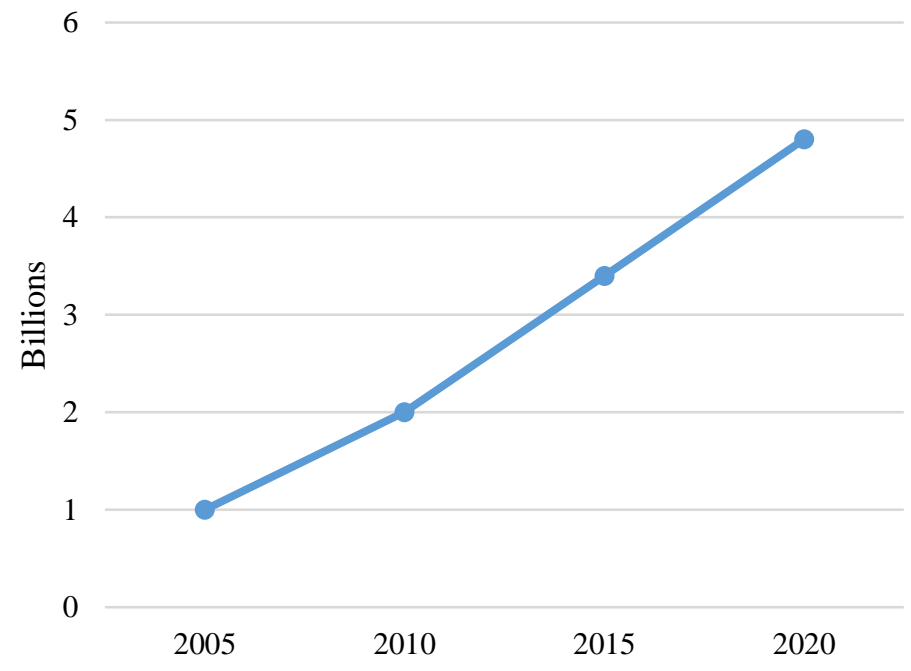

Fig. 2. Dynamics of the growth of the number of Internet users in the world (compiled by the authors).

Using social networks to promote higher education institutions creates an image of a modern, following the development of the university. The annual growth in the number of users of social networks is $10.5 \%$, and today about 4 billion people have registered in at least one social network. [10] Facebook and YouTube were the most popular non-gaming social platforms in 2020. (Fig. 3)

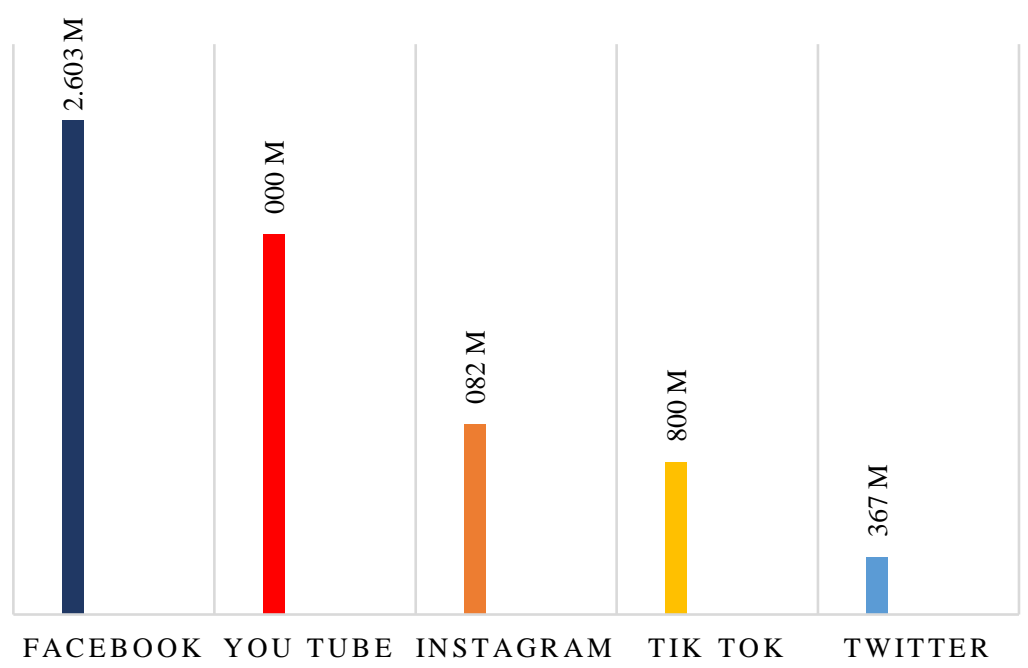

Fig. 3. Number of non-gaming social app installs in 2020 (compiled by the authors).

If we talk about age groups, most social networks are for an audience of $13+$. However, the main audience of social networks is young people aged 16-35 years - potential consumers of educational services. This section presents the results of the study. Here you can use tables, figures and formulas. An example of table design is presented below (table 1). 


\section{Discussion}

Although there are more than enough marketing tools to promote educational services on the Internet, they are not used enough. This is often due to insufficient funding and underestimation of the effectiveness of not only Internet marketing, but also marketing in general. Reluctantly investing in marketing, the university management demonstrates its skepticism towards the promotion of services [11]. Progress leads to a rapid loss of relevance of information; market volatility affects the decline in the effectiveness of some marketing tools. Not all universities follow trends and update information using outdated methods of promotion that do not bring results. Hence the reluctance to invest in ineffective goals.

Social networks allow you to gather and divide the audience by interests and focus it in one place, where they can receive interesting information, leave suggestions and questions. The advantage of using social networks to promote educational institutions is an informal way to communicate with future applicants. With the help of a social network, they can communicate with real students and graduates, thereby forming an opinion about the university.

Thus, social networks are a successful promotion tool, thanks to which the university carries out the following:

- create contact with your students to improve the conditions of the educational process;

- informing students, applicants and graduates about the events and highlights of the university's social life;

- improving the image of the university;

- increase loyalty to the university.

The university in order to attract applicants and convince the feasibility of acquiring educational services presents the parameters of the services offered very clearly, using diplomas, licenses, certificates, and so on. The consumer presents the offered services as not conserved. It is common for a person to forget the information received, and the knowledge gained in the course of scientific and technological progress becomes obsolete. That is why the marketing of educational services should combine both external and internal PR factors. [7].

Thus, in order to determine the essence of Internet marketing, its constituent elements were analyzed. Marketing is being actively introduced into the higher education system, the value of which is growing every year. To position themselves in the market, universities have resorted to using its various tools, and in modern conditions, Internet marketing is becoming more popular. Today, thanks to the use of its relevant and effective elements, the well-being of the university in the long term is ensured.

\section{Conclusion}

Internet marketing in the field of higher education has great prospects. The uniqueness of this type of marketing is its accessibility. The Internet space has no restrictions, and the necessary information is provided almost instantly.

Based on this, the Internet is an ideal platform for creating and maintaining the image of the university, as well as attracting potential consumers of educational services. The most convenient way to do this is to use social networks that perform a certain age segmentation. As a result, there is a high probability that the information will reach the right consumer. Aside from that, the information provided will be reliable, as it comes from an official source. Applicants and students are involved in the social life of the university. Interactive communication provides an opportunity to maintain a dialogue with students, solve problems, answer questions and respond to feedback. 
The university's website is another effective channel of attraction. This is the "business card" of the university, which makes it possible to assess the interest of applicants, the relevance of information and events posted on the site.

The advantage of Internet marketing is the low cost, which makes it possible to use more marketing tools with a relatively similar budget. Besides, there is a wide variety of easy ways to evaluate online marketing activities through surveys, questionnaires, and site search query analysis.

Thus, the task of Internet marketing in the field of higher education is to create and maintain up-to-date information about the university, which is broadcast on the website, the official pages of the university for its further positioning.

The article was written within the framework of grant funding for scientific research under the project AP09057847 «Formation and development of the knowledge economy in the context of digitalization of the Republic of Kazakhstan: conceptual foundations and prospects for implementation».

\section{References}

1. How much do Kazakhstan companies spend on advertising in social networks, https://forbes.kz/

2. What countries do Kazakh students study. https://kursiv.kz/

3. L.B. Vanchikova, L.S. Koksharova, Bulletin of the Trans-Baikal State University 22(2) (2016)

4. Official website of the Bureau of National Statistics of the Agency for Strategic Planning and Reforms of the Republic of Kazakhstan, https://stat.gov.kz/

5. Online Advertising Market-Growth, Trends, Covid-19 Impact, And Forecasts (20212026), https://www.mordorintelligence.com/

6. J. Cashman, M. Treece, Digital Firefly Marketing Edition, 103 (2014)

7. S. Ziyadin, A. Serikbek, ISCDTE 2019 (2020)

8. D.A. Shevchenko, Sociological research 5(361), 143 (2014)

9. Internet Usage Statistics, https://www.internetworldstats.com/

10. The number of users of social networks around the world from 2017 to 2025 , https://www.statista.com/

11. C. Chapleo, Int. J. Educ. Adv. 5(1), 7 (2004) 